\title{
ASSESSMENT OF ENVIRONMENTAL CAUSES OF MATERNAL OBESITY AND ITS EFFECTS ON FETAL DEVELOPMENT
}

\author{
Awadallah, Hala ${ }^{(1)}$; El Kadi, M. A. H. ${ }^{(2)}$; Niazi, G. M. ${ }^{(3)}$ \\ and Al Sirgany, Ola, A. A. ${ }^{(4)}$ \\ 1) Institute of Environmental Studies and Research, Ain Shams University \\ 2) Obstetrics and Gynecology Department Ain Shams University \\ 3) Department of Radio diagnosis Ain Shams University 4) Special Care \\ Center for the Fetus Ain Shams Maternity Hospital, Ain Shams University
}

\begin{abstract}
Maternal obesity is a growing problem worldwide leading to physical and psychological problems to the mother and everyone around her. The aim of this study is to reflect the association between maternal obesity and fetal macrosomia. In this study 100 cases and 100 controls were selected from pregnant women who were referred from outpatient clinics to the Special care unit for the fetus; Ain Shams University Maternity Hospital for ultrasound examination in the period from July 2013 to January 2015. The results of this study showed significant effect of obesity on the gestational age of the fetus calculated by the ultrasound (US) compared to fetal age according to the last menstrual period (LMP) as the mean US gestational age for the cases was $31.55 \pm$ 1.7 SD compared to $29.86 \pm 1.3 \mathrm{SD}$ according to LMP and $29.74 \pm$ 1.3 SD for gestation age according to ultrasound for controls and $29.68 \pm 1.3$ SD for gestation age according to LMP for controls. Also fetal weight was higher in cases with mean of $1819.73 \pm 223.98$ compared to $1514.59 \pm$ 223.98.hence more attention should be directed to this major public health problem to raise the awareness and provide more clinical care and medical service for these pregnant women and their babies.
\end{abstract}

Key words: Maternal obesity, body mass index, gestation age, fetal development, fetal macrosomia. 
J. Environ. Sci.

Institute of Environmental Studies and Research - Ain Shams University

\section{INTRODUCTION}

Obesity prevalence in the general population has increased substantially in the past 20 years, what is even more alarming is the number of women of childbearing age who are overweight or obese. (Morin and Reilly 2007).

The prevalence of maternal obesity was $14 \%$. Increasing BMI was independently associated with increasing risk of adverse obstetric and neonatal outcome, Caesarean sections could be avoided if all obese women were of normal BMI. (Oteng-Ntim, et al., 2013).

Increased prevalence of maternal obesity is of great concern as it has been found to be associated with adverse health outcomes affecting both the mother and her fetus, neonate and child. Unfortunately, the association between obesity and adverse pregnancy outcomes is not universally acknowledged, which only serves to perpetuate the problem (Yogev and Catalano, 2009).

Obesity usually results from a combination of causes and contributing factors, including genetic factors, which may affect the amount of stored body fat where that fat is distributed, inactivity, unhealthy diet and eating habits especially eating fast food and skipping breakfast, family lifestyle as family members tend to have similar eating, lifestyle and activity habits, quitting smoking, lack of sleep which can cause changes in hormones that increase appetite, certain medications including some antidepressants, anti-seizure medications, diabetes medications, antipsychotic medications, steroids and beta blockers, social and economic issues. (MFMER; 2012). 
Recent research has suggested that the in utero environment may program the fetus for elevated risk of later obesity, attempts to prevent obesity prior to becoming pregnant are crucial. At the very least, interventions must aim to limit excessive weight gain during pregnancy. (Saskatchewan Prevention Institute 2010).

Pre-existing maternal as well as gaining too much weight during pregnancy has been linked with poor pregnancy outcomes which can result in the delivery of a large-for-gestational-age (LGA) baby or macrosomia. Macrosomia has been associated with adverse maternal and neonatal outcomes, including caesarean birth, prolonged labour, birth trauma, cephalopelvic disproportion, birth asphyxia, and increased risk of perinatal mortality (Zhang, et al 2008), that's why the topic of gestational weight gain is indeed worthy of further attention and investigation (Saskatchewan Prevention Institute 2010).

Since it was introduced to medical field; ultrasound could be used to determine fetal age, evaluate multiple and/or high-risk pregnancies, detect fetal and placental abnormalities, identify structural problems with the uterus, and determine other abnormalities (Tomas; 2011).

The aim of the current study is to assess the effects of maternal obesity on fetal development.

\section{SUBJECTS AND METHODS}

\section{Subjects:}

A cross sectional study was done over a period of 18 months over 100 obese pregnant females who were chosen from women who were referred to 
the Special care unit for the fetus according to their pre pregnancy BMI with 100 non obese pregnant females taken as controls.

The study was performed on pregnant women presenting to the Special Care Unit for the fetus, Ain Shams University Maternity Hospital for regular antenatal care, between 28 weeks and 32 weeks of gestation with BMI 30 kilogram per meter squared or above according to their pregravid (Before pregnancy) weight. Age predilection of pregnant women between 16 and 42 years old in the period from July 2013 to January 2015.

Exclusion criteria were; Women with multiple pregnancies, patients with Diabetes Mellitus, patients with Hypertension, patients with any other comorbidity that can affect the fetus, patients with known exposure to radiation during pregnancy.

\section{Methodology:}

An informed oral consent was taken from all the cases with all information about the study objectives as well as the study tools like the questionnaire they had to answer and the investigations they had to do e.g.(ultrasonography). Confidentiality of their data was assured and they were informed that their results will be told to them. Broad results and recommendations of the study would also be given to them orally upon their request in the future. Full obstetric history of previous pregnancy outcomes with special consideration to fetal weight and congenital anomalies as well as mode of delivery (Vaginal or Cesarean Section) were taken. Also full medical history was taken including DM, HTN, Cardiac disease, high cholesterol levels. 
Weight (pre-gravid) and Height measurement were acquired in order to calculate the body mass index (BMI). Body mass index is defined as the individual's body mass divided by the square of their height. The formulae universally used in medicine produce a unit of measure of $\mathrm{kg} / \mathrm{m}^{2}$. Women who are overweight for their height are at increased risk of problems during pregnancy. Most women put on 10-12.5kg (22-28lb) in pregnancy which will be considered.

$$
\mathrm{BMI}=\frac{\operatorname{mass}(\mathrm{kg})}{(\operatorname{height}(\mathrm{m}))^{2}}
$$

The World Health Organization ( $\underline{\mathrm{WHO}}$ ) regards a BMI of less than 18.5 as underweight and may indicate malnutrition, an eating disorder, or other health problems, while a BMI greater than 25 is considered overweight and above 30 is considered obese. These ranges of BMI values are valid only as statistical categories (WHO; 2006)

Table 1: Categories of BMI quoted from WHO 2015

\begin{tabular}{||l|c|}
\hline \multicolumn{1}{|c|}{ Category } & BMI range $-\mathbf{~ k g} / \mathbf{m}^{\mathbf{2}}$ \\
\hline Very Severely underweight & less than 15 \\
\hline Severely underweight & from 15.0 to 16.0 \\
\hline Underweight & from 16 to 18.5 \\
\hline Normal (healthy weight) & from 18.5 to 25 \\
\hline Overweight & from 25 to 30 \\
\hline Obese Class I (Moderately obese) & from 30 to 35 \\
\hline Obese Class II (Severely obese) & from 35 to 40 \\
\hline Obese Class III (Very severely obese) & Over 40 \\
\hline
\end{tabular}


Two dimensional ultrasonography for measuring fetal biometry including Biparietal diameter (BPD), Head Circumference, Femur length (FL) and Abdominal circumference (AC) and comparing with gestational age. Fetal weight will be calculated by the machine using the biometry data.

Fetal anomaly diagnoses were grouped according to their likely clinical consequences as suggested by the Royal College of Obstetricians and Gynecologists. The patients will be consented for the use of their data for scientific research. Results obtained will be statistically analyzed to describe range, mean, standard deviation, median and percentages comparisons of the 2 groups was done concerning the fetal biometry and weight as well as complications.

\section{RESULTS}

Table 2: Comparison between the studied groups regarding the Age, prepregnancy weight and BMI and fetal weight

\begin{tabular}{|l|c|c|c|c|}
\hline & \multicolumn{1}{|c|}{ Case } & Control & T & P \\
\hline \hline $\begin{array}{l}\text { Age } \\
\text { Mean } \pm \text { SD }\end{array}$ & $29.83 \pm 5.605$ & $27.80 \pm 4.979$ & 2.708 & 0.007 \\
\hline $\begin{array}{l}\text { Pre-pregnancy } \\
\text { weight } \\
\text { Mean } \pm \text { SD }\end{array}$ & $97.96 \pm 8.901$ & $61.39 \pm 3.887$ & 37.651 & 0.0001 \\
\hline $\begin{array}{l}\text { Height } \\
\text { Mean } \pm \text { SD }\end{array}$ & $165.24 \pm 7.413$ & $164.07 \pm 5.113$ & 1.229 & 0.195 \\
\hline $\begin{array}{l}\text { BMI } \\
\text { Mean } \pm \text { SD }\end{array}$ & $35.99 \pm 3.827$ & $23.10 \pm 2.109$ & 29.489 & 0.0001 \\
\hline $\begin{array}{l}\text { Mean Fetal weight } \\
\text { Mean } \pm \text { SD }\end{array}$ & $1819.73 \pm 223.983$ & $1514.59 \pm 178.322$ & 10.658 & 0.005 \\
\hline
\end{tabular}


Table 2 results showed maternal age of mean of 29.83 years \pm 5.605 SD for cases and 27.8 years $\pm 4.979 \mathrm{SD}$ for controls. Mean pre-pregnancy weight for cases was $97.96 \mathrm{~kg} \pm 8.9 \mathrm{SD}$ compared to $61.93 \mathrm{~kg} \pm 3.9 \mathrm{SD}$ for controls with $p$ value $\leq 0.0001$.

Maternal height showed a mean of $165.24 \mathrm{~cm} \pm 7.4$ SD for cases $164 \mathrm{~cm}$ \pm 5.1 for controls and a mean of BMI of $35.99 \pm 3.82$ for cases compared to $23.1 \pm 2.1$ SD for controls. Also fetal weight was higher in cases with mean of $1819.73 \pm 223.98 \mathrm{SD}$ compared to $1514.59 \pm 223.98 \mathrm{SD}$ for controls with $\mathrm{p}$ value $\leq 0.005$.

Table 3: Comparison between the case and control groups as regard the

Consanguinity and obesity among family members

\begin{tabular}{|c|c|c|c|c|c|c|}
\hline Variables & \multicolumn{2}{|c|}{$\begin{array}{c}\text { Case } \\
\mathbf{n}=100 \text { ) }\end{array}$} & \multicolumn{2}{|c|}{$\begin{array}{l}\text { Control } \\
(n=100)\end{array}$} & $x^{2}$ & P value \\
\hline \multicolumn{7}{|c|}{ Consanguinity } \\
\hline Yes & 61 & 61 & 44 & 44 & 9.191 & 0.010 \\
\hline No & 39 & 39 & 56 & 56 & & \\
\hline \multicolumn{7}{|c|}{ Obesity among family members } \\
\hline Yes & 85 & 85 & 45 & 45 & 151.5 & 0.000 \\
\hline No & 15 & 15 & 55 & 55 & & \\
\hline
\end{tabular}

In Table 3 Consanguinity represented 61 percent among cases and 44 percent among controls with $\mathrm{p} \leq 0.010$ as for obesity among family members the results were positive in 85 percent in cases and 45 percent in the control group with $\mathrm{p} \leq 0.0001$. 
Table 4: Comparison between mean gestation age according to the last menstrual period (LMP) and Mean gestation age according to ultrasound among studied groups

\begin{tabular}{|l|c|c|c|c|}
\hline & $\begin{array}{c}\text { Gestation age } \\
\text { according to LMP } \\
\text { Mean } \pm \text { SD }\end{array}$ & $\begin{array}{c}\text { Gestation age by to } \\
\text { ultrasound } \\
\text { Mean } \pm \text { SD }\end{array}$ & T & P value \\
\hline Case & $29.86 \pm 1.371$ & $31.55 \pm 1.7$ & $-0,786$ & 0.0001 \\
\hline Control & $29.68 \pm 1.377$ & $29.74 \pm 1.3$ & $-11,007$ & 0.434 \\
\hline
\end{tabular}

Table 4 showed the mean US gestational age for the cases was $31.55 \pm$ 1.7 SD compared to $29.86 \pm 1.3 \mathrm{SD}$ according to LMP and $29.74 \pm 1.3 \mathrm{SD}$ for gestation age according to ultrasound for controls and $29.68 \pm 1.3 \mathrm{SD}$ for gestation age according to LMP for controls.

Table 5: Comparison between the studied groups regarding the women's education.

\begin{tabular}{|c|c|c|c|c|c|c|}
\hline Women's & \multicolumn{2}{|c|}{$\operatorname{Case}(n=100)$} & \multicolumn{2}{|c|}{ Control $(n=100)$} & \multirow[b]{2}{*}{$\chi^{2}$} & \multirow{2}{*}{$P$ value } \\
\hline Education & No. & $\%$ & $\mathrm{Nc}$ & $\%$ & & \\
\hline Illiterate & 11 & 11 & 9 & 9 & \multirow{6}{*}{12.448} & \multirow{6}{*}{0.29} \\
\hline Primary school & 7 & 7 & 3 & 3 & & \\
\hline Preparatory school & 22 & 22 & 11 & 11 & & \\
\hline High school & 30 & 30 & 29 & 29 & & \\
\hline College graduate & 30 & 30 & 42 & 42 & & \\
\hline Postgraduate & 0 & 0 & 6 & 6 & & \\
\hline
\end{tabular}

Table 5 reflects the level of education where $11 \%$ of the cases were illiterate compared to 9 cases in controls, $7 \%$ went to 1ry school compared to $9 \%$ in controls $22 \%$ went to preparatory schools in cases compared to $11 \%$ in controls, $30 \%$ of the cases received high school education compared to $29 \%$ in the controls as regarding college graduates there were $30 \%$ for the cases 
and $42 \%$ for the controls, none of the cases were postgraduates compared to $6 \%$ of the controls.

Table 6: Comparison between the studied groups regarding women's occupation

\begin{tabular}{|l|c|c|c|c|c|c||}
\hline \multicolumn{1}{|c|}{ Occupation } & \multicolumn{2}{|c|}{ Case $(\mathbf{n}=\mathbf{1 0 0})$} & \multicolumn{2}{c|}{ Control $(\mathbf{n = 1 0 0})$} & $\chi^{2}$ & P value \\
& No. & No. & \% & & \\
\hline \hline House wife & 38 & 38 & 18 & 18 & & \\
Employee & 52 & 52 & 60 & 60 & 10.808 & 0.004 \\
other & 10 & 10 & 22 & 22 & & \\
\hline
\end{tabular}

Table 6 represents occupation 38\% of cases were housewives compared to only $18 \%$ of the controls $52 \%$ of cases were employee compared to $60 \%$ of controls and $10 \%$ of cases had other occupations compared to $22 \%$ of controls with a $\mathrm{p}$ value $\leq 0.004$.

\section{DISCUSSION}

In this study 100 cases and 100 controls were selected from pregnant women who were referred from outpatient clinics to the Special care unit for the fetus; Ain Shams University Maternity Hospital for ultrasound examination in the period from July 2013 to January 2015.

Regarding maternal age showed a mean of 29.83 years for cases and 27.8 years for controls. Mean pre-pregnancy weight for cases was $97.96 \mathrm{~kg} \pm 8.9$ $\mathrm{SD}$ compared to $61.93 \mathrm{~kg} \pm 3.9 \mathrm{SD}$ which was highly significant. However maternal height was close for both cases and controls with mean of 165.24 $\mathrm{cm}$ for cases $\pm 7.4 \mathrm{SD}$ and $164 \mathrm{~cm} \pm 5.1$ for controls resulting in mean BMI of $35.99 \pm 3.82$ for cases compared to $23.1 \pm 2.1$ SD for controls. Which we found highly significant with fetal macrosomia As Pregnant women were 
referred to us in the third trimester with similar mean gestational age for both cases and controls 29.64 weeks of gestation \pm 1.4 SD.

As for consanguinity; Consanguinity was also found to be significant which was 61 percent among cases and 44 percent among controls with $\mathrm{p}$ value 0.010 where no associated congenital anomalies in both cases nor control groups which is in disagreement with a study done by Maghsoudlou et al,(2005) which showed increased stillbirth risk [odds ratio (OR) 1.53; $95 \%$ CI 1.10-2.14]. The association was significantly increased for preterm stillbirth (<37 gestational weeks) (OR 2.43; 95\% CI 1.46-4.04) but not for term stillbirth ( $\geq 37$ weeks) (OR 1.14; 95\% CI 0.75-1.74). Low and high maternal age, underweight, obesity, nulliparity, a history of infertility or miscarriage, previous obstetric complications (preeclampsia, preterm delivery, and stillbirth in previous pregnancies) were also associated with increased stillbirth risks.

As for obesity among family members; Obesity among family was apparently related to women's obesity as $85 \%$ of the cases reported that they have obese members among their family members compared to only $45 \%$ of the controls with $\mathrm{p}$ value 0.0001 which is in agreement to a study done showing The prevalence of familial clustering of overweight and obesity was $75.3 \%$ and $20.3 \%$, respectively. The prevalence of overweight in firstgeneration (parents) and second-generation (grandparents) relatives was $54.6 \%$ and $53.1 \%$, respectively. There was a linear trend toward correlation between age and the rates of overweight and obesity. The familial clustering 
of obesity with family income reached statistical significance. (Zengning, et al., 2014)

According to results of this study there was significant affection of obesity on the US gestational age compared to LMP as the mean US gestational age for the cases was $31.55 \pm 1.7 \mathrm{SD}$ and $29.74 \pm 1.3 \mathrm{SD}$ for controls even though both cases and controls have nearly similar mean gestation age according to LMP. Also fetal weight was higher in cases with mean of $1819.73 \pm 223.98$ compared to $1514.59 \pm 223.98$ among controls. This is with agreement with a study done in the Department of Research, The American College of Obstetricians and Gynecologists, Washington, DC discussing The major concern in obese pregnant women is fetal macrosomia, which appears to be increased 2- to 3-fold in obese patients (Ehrenberg et al 2004) Moreover this agrees with a study showing a dose-dependent relationship between maternal obesity and fetal macrosomia. In a recent metaanalysis, the prevalence rates of fetal macrosomia were $13.3 \%$ and $14.6 \%$ for obese and morbidly obese women, respectively, compared with $8.3 \%$ for the normal weight control group. In the United States, the mean birth weight between 1985 and 1998 increased from 3423 to $3431 \mathrm{~g}$ among whites and from 3217 to $3244 \mathrm{~g}$ among blacks. In Canada during the same time period, the mean birth weight increased from 3391 to 3427.28 In Denmark, the mean birth weight between 1990 and 1999 increased from $3474 \mathrm{~g}$ to $3519 \mathrm{~g}$ (an increase of $45 \mathrm{~g}$ ) and macrosomia rates increased from $16.7 \%$ to $20 \% .29$ During a similar time period (1992-2001) in Sweden, there was a 3\% increase in the incidence of large for-gestational-age newborns (Surkan et al 2004). 
Also this concurs with another study on the global increase in the prevalence of fetal macrosomia, the prevailing data suggested that maternal obesity is the main factor, followed by maternal diabetes status. Fetal macrosomia in obese women is associated not only with an increase in the absolute size of the fetus, but also in a change in body composition (Sewell et al 2006).

Sewell et al., (2006) found that the average fat mass of infants born to mothers with a normal BMI $\left(25 \mathrm{~kg} / \mathrm{m}^{2}\right)$ was $334 \mathrm{~g}$, giving a body fat composition of $9.7 \%$. The offspring of women with a BMI $25 \mathrm{~kg} / \mathrm{m} 2$, on the other hand, had a mean fat mass of $416 \mathrm{~g}$, or a body fat composition of $11.6 \%$. Of note, the majority of this effect appears to be a result of weight gain during pregnancy. Indeed, pre-pregnancy BMI appears to account for only $6.6 \%$ of the observed variation in infantile fat mass and only $7.2 \%$ of body fat composition.

As for education $11 \%$ of the cases were illiterate compared to 9 cases in controls, $7 \%$ went to 1ry school compared to $9 \%$ in controls $22 \%$ went to preparatory schools in cases compared to $11 \%$ in controls, $30 \%$ of the cases received high school education compared to $29 \%$ in the controls as regarding college graduates there were $30 \%$ for the cases and $42 \%$ for the controls, none of the cases were postgraduates compared to $6 \%$ of the controls. Thus we can say that average maternal weight could be attributed to higher level of education, this is in agreement with a study done by Ruager-Martin et.al;(2010) on Risk factors of maternal overweight and obesity and excessive gestational weight gain In the multivariate analyses, showing maternal low 
educational level as a significant risk factor for maternal obesity with all Pvalues $<0.05$.

As for occupation $38 \%$ of cases were housewives compared to only $18 \%$ of controls, which states that staying at home is related to increased maternal weight with a $\mathrm{p}$ value $\leq 0.004$ which is in agreement to a study done by $\mathrm{Li}$ Ming Wen, 2013 showing a significant relation between housewives and female workers regarding maternal obesity with $\mathrm{p} \leq 0.17$.

In conclusion maternal obesity was found to have a significant impact on fetal growth pattern and the occurrence of fetal macrosomia.

It is recommended that more attention should be directed to this major public health problem to raise the awareness and provide more clinical care and medical service for these pregnant women and their babies.

\section{REFERENCES}

Bhattacharya S, Campbell DM and Liston WA. (2007): Effect of body mass index on pregnancy outcomes in nulliparous women delivering singleton babies; BMC Public Health; 167:168.

doi: $10.1186 / 1471-2458-7-168$.

Ehrenberg H, Mercer B, Catalano P. (2004): The influence of obesity and diabetes on the prevalence of macrosomia. Am J Obstet Gynecol; 191(3):964-8.

Li Ming Wen, Med, Judy M. Simpson, Chris Rissel, and Louise A. Baur;(2013): Maternal "Junk Food" Diet During Pregnancy as a Predictor of High Birthweight: Findings from the Healthy Beginnings Trial ; Am J Obstet Gynecol BIRTH 40(1):46-51.

Maghsoudlou S,Cnattinquis S and Aarabr M; (2015): Consanguineous marriage, prepregnancy maternal characteristics and stillbirth risk: a population-based case-control study. Acta Obstet Gynecol Scand ; (10):1095-101. doi: 10.1111/aogs.12699. 
Mayo Foundation for Medical Education and Research (MFMER). Aug. 3, 2012. Mayoclinic.com/health/obesity.

Morin, K. H., and Reilly, L. (2007): Caring for obese pregnant women, JOGNN, 36, 482-489.

Oteng-Ntim E, Kopeika J, Seed P, Wandiembe S and Doyle P. (2013): Impact of obesity on pregnancy outcome in different ethnic groups: calculating population attributable fractions; PLoS One. 8(1):e53749. doi: 10.1371.

Ruager-Martin R, Hyde MJ and Modi N. (2010): Maternal obesity and infant outcomes. Early Human Development; 86(11):715-22. doi: 10.1016.

Saskatchewan Prevention Institute May (2010): Maternal obesity, excessive weight gain and pregnancy outcomes final report. Available at:http://www.skprevention.ca/wp-content/uploads/2010/01/ Maternal_Obesity_Excessive_Gestational_Weight_Gain.

Sewell MF, Huston-Presley L, Super DM and Catalano P. (2006): Increased neonatal fat mass, not lean body mass, is associated with maternal obesity. Am J Obstet Gynecol; 195: 1100-1103.

Surkan PJ, Hsieh CC and Johansson AL. (2004): Reasons for increasing trends in large for gestational age births. Obstet Gynecol; 104: 720-726.

Tomas Kellner (2011): 4D Ultrasound Technology; GE Reports. http://www.gereports.com/post/92446012480.

WHO (World Health Organization) (2006): Body mass index http://www.who.int/mediacentre/factsheets/fs311/en.

Yogev, Y. \& Catalano, P. M.(2009): Pregnancy and obesity. Obstet Gynecol Clin N Am, 36, 285-300.

Zengning Li, Bin Luo, Limei Du, Huanyu Hu, and Ying Xie;(2014): Familial clustering of overweight and obesity among schoolchildren in northern China Int J Clin Exp Med.; 7(12): 5778-5783.. 
Zhang, X., Decker, A., Platt, R. W., and Kramer, M. S. (2008): The perinatal consequences of fetal macrosomia. American Journal of Obstetrics \& Gynecology, 517.e1- 517.e6.

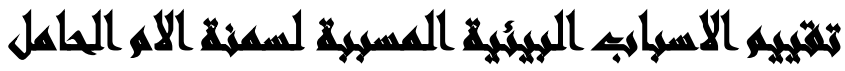

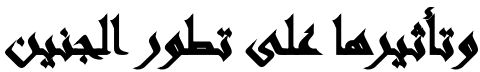

[r]

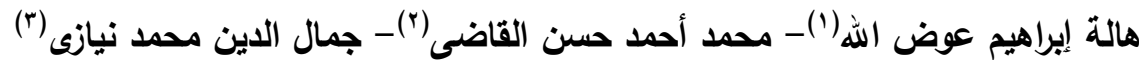

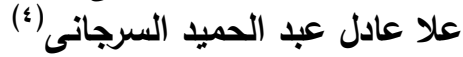

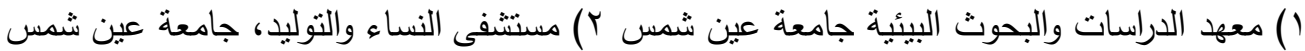

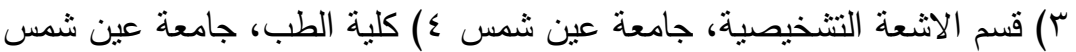

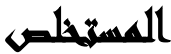

بدانة الأم هي مشكلة مثتامية في جميع أنحاء العالم مما يؤدي إلى مشاكل جسدية ونفسية للأم العام

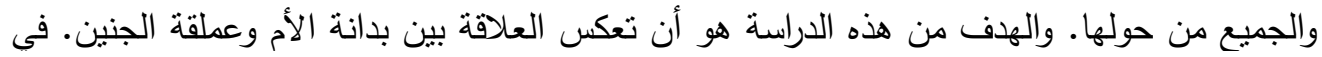

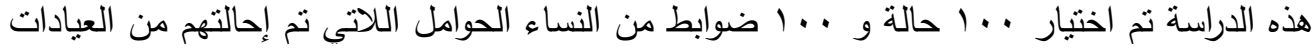
الخارجية إلى وحدة العناية الخاصة للجنين. مستتفى النساء والتوليد جامعة النياء عين شمس لفحص

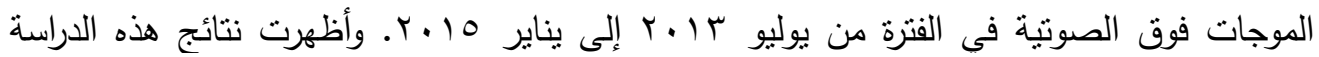

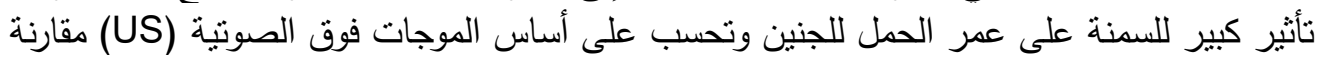

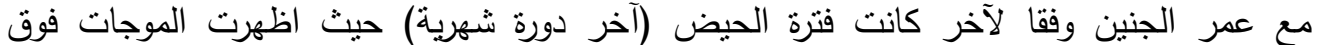

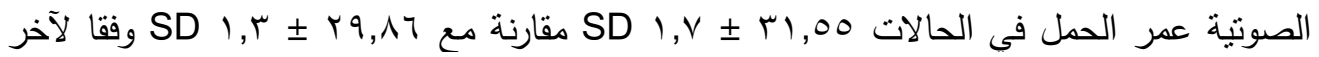

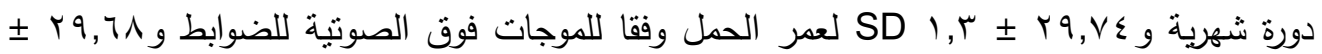

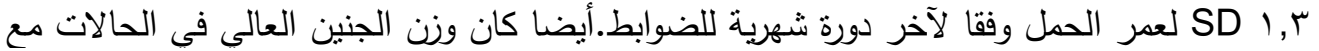

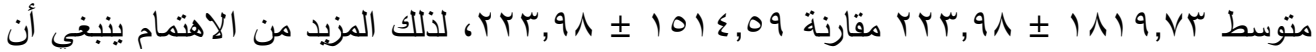

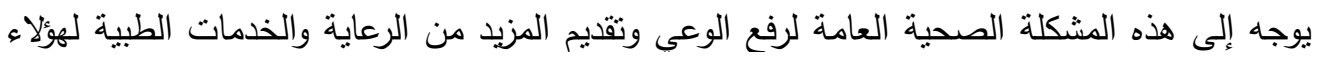

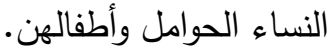

